\title{
LAUDATIONES ET INIURIAE: DEBATE SOBRE UM ASPECTO DA CONSTRUÇÃO DA IMAGEM DO GOVERNANTE EM SÊNECA ${ }^{1}$
}

\author{
Willian Mancini` \\ Universidade Federal de Ouro Preto \\ Fábio Faversani $\star \star$ \\ Universidade Federal de Ouro Preto
}

\begin{abstract}
The article aims to understand specific aspects of the relations between emperors and aristocrats, especially regarding the role of clemency in the making of these relationships. The authors analyse this issue in the context of the principates of Claudius and Nero in three works of Seneca (De consolatione ad Polybium, Apolococintosis, Declementia).

KEYWORDS: Seneca; Claudius; Nero; clemency; Roman empire; aristocracy.
\end{abstract}

- o analisarmos a Consolação a Políbio, de Sêneca, percebemos que o autor expõe em sua obra dois temas recorrentes na sociedade da Roma Imperial: o servilismo da aristocracia para com o imperador e sua corte e o reconhecimento das qualidades do governante ideal. Avaliamos neste artigo como a Consolatio em questão traz à tona essas duas ideias, comparando suas características com o que encontramos em outras duas obras de Sêneca que tratam dos mesmos assuntos, a saber,

^willian_his2005@hotmail.com

$\star \star$ faversan@ichs.ufop.br

${ }^{1}$ Pesquisa realizada com apoio do CNPq, através de seu edital Universal. Ambos os autores são membros do Laboratório de Estudos sobre o Império Romano (LEIR). 
Apocolocintose, sátira menipeia composta para servir de "damnatio memoriae" de Cláudio, e o Tratado sobre a Clemência, escrito como instrução para o governo de Nero, que sucedeu a Cláudio e de quem Sêneca foi preceptor. Mostraremos de que maneira o filósofo e poeta utiliza do contexto histórico da sociedade romana de sua época para construir habilmente (por não se tratar de um elogio sincero) as ideias expressas nesta carta consolatória.

Antes, porém, de avançar na análise, cumpre recuperar algumas informções relativas ao pensador de que trataremos e ao contexto histórico em que ele viveu. Lúcio Aneu Sêneca, natural de Córdova, então província da Hispânia, nasceu por volta do ano 4 a.C. e morreu em 65 d.C. Ainda na infância mudou-se para Roma, iniciando seus estudos com o retor e filósofo Papírio Fabiano, o estóico Átalo, o cínico Demétrio e o neopitagórico Sócion. Mais tarde, provavelmente por motivos de saúde, seguiu para o Egito, onde era prefeito o marido de sua tia materna. Alguns anos depois da viagem, regressou com a tia para Roma e, por intermédio desta, conseguiu a questura. Nesse novo ambiente é que Sêneca atinge o que foi o auge de sua carreira até então.

Em 39 d.C., no entanto, o filósofo atrai a ira de Caio César, o imperador Calígula, ao pronunciar um discurso que desagradou o príncipe. Dion Cássio afirma que o poeta quase foi levado à morte por esta razão. Em janeiro de 41 d.C., Calígula é assassinado e temos a ascensão de Cláudio. Mas, no final deste mesmo ano, Sêneca sofre novo revés: tendo sido acusado de adultério e enviado ao exílio, lá permanece por oito anos.

É neste momento difícil que o pensador estoico endereçou uma Consolatio para Políbio, importante liberto da corte claudiana que teve os encargos de a studiis (encarregado da biblioteca) e a libellis (responsável pelas solicitações feitas ao imperador). ${ }^{3}$ Esse perfil fez de Políbio o atalho perfeito para que chegasse ao imperador o clamor de Sêneca. ${ }^{4} \mathrm{~A}$

\footnotetext{
${ }^{2} \mathrm{O}$ termo, que significa, literalmente, "a condenação da memória", no sentido de "remover da lembrança", denominava uma forma de censura pública, uma desonra que poderia ser aprovada pelo Senado a traidores ou a quaisquer outros indivíduos que trouxessem descrédito para o Estado romano.

${ }^{3}$ As referências à posição de a studiis estão em Suetônio (Claud. 28); menções de $a$ libellis encontram-se na própria carta consolatória (VI, 5).

${ }^{4}$ É como opina Pierre Grimal, em sua biografia do filósofo latino. Para o estudioso francês, o liberto era verdadeiramente erudito e estava à altura de receber e acolher favoravelmente, por compreendê-los, os argumentos do peticionário (cf. Grimal, P. Sénèque. Paris: Fayard, 1978, p. 100). Opinião contrária tem René Waltz, que nega qualquer elevação intelectual ao liberto e qualificou a carta como des lignes si deshonorantes (cf. Waltz, R. Vie de Sénèque. Paris: Perrin, 1909, p. 115).
} 
morte do irmão do liberto trouxe o pretexto para a carta consolatória contendo também elogios adulatórios a Cláudio.

Contudo, tais adulações não serviram aos propósitos de Sêneca. Ao contrário, fazendo tais encômios ao César, o escritor que visava obter dele o perdão através do seu poderoso liberto não logrou favores. O retorno de Sêneca a Roma, em 49 d.C., narrado por Tácito, ${ }^{5}$ deu-se por intermédio de Agripina, que o havia conhecido antes de ser exilada por Calígula. Agripina intercedeu junto a Cláudio por Sêneca, solicitando que ele viesse a Roma para ser preceptor do filho dela.

Nero, que acabara de ser adotado por Cláudio, passava a ser o mais próximo na sucessão ao trono, ao lado de Britânico, filho de Cláudio com Messalina. Com o movimento nada desinteressado de aproximar-se do filósofo, Agripina visava a atingir três objetivos: conquistar para seu filho o favor popular, mostrando que ele realmente estava sendo instruído por um dos grandes sábios da época; transformar o jovem, educando-o da melhor maneira possível; conquistar a gratidão de Sêneca, facilitando assim o controle dela sobre o filho através do seu preceptor. Vale dizer, então, que Sêneca volta do exílio diretamente para o centro das perigosas disputas pelo poder em Roma.

Entretanto, o filósofo de Cordova não se submeteu ao último desígnio de Agripina; mas, de modo adverso, tentou criar em Nero um príncipe perfeito, um sábio que reinaria por sua capacidade, em harmonia com as virtudes necessárias. Grande parte dessa disciplina aplicada por Sêneca a Nero se encontra teorizada no De clementia, tratado político escrito justamente quando Nero inicia seu governo - em que Sêneca mostrava ao discípulo a importância e o uso correto da clemência, seguindo o modelo de Augusto.

Após a morte de Cláudio, provavelmente vítima de envenenamento a mando de Agripina em 54 d.C., Sêneca compôs uma sátira menipeia a fim de atacar seu antigo desafeto, o César que o havia exilado por tão longo e penoso período. ${ }^{6}$ Junto a esse ataque à figura de Cláudio, há também, na obra, um elogio ao novo imperador. Em contraste com Cláudio, que deixava o poder, Sêneca apresenta uma imagem de Nero equiparado a Apolo, o deus sol, demonstrando que se dissipavam as

\footnotetext{
${ }^{5}$ Tácito, Anais XII, 8, 2.

${ }^{6}$ Cf. Wiedeman, T. E. J. Tiberius to Nero. In: Bowman, A. K.; Champlin, E.; Lintott, A. (Org.). Cambridge Ancient History. Vol. X. The Augustan Empire, 43 B.C. A.D. 69. Cambridge: University Press, 2008, p. 229.
} 
trevas e que a partir do início do seu principado começava a era das luzes. ${ }^{7}$

Depois da morte de Afrânio Burro, aliado do filósofo contra as ambições de Agripina, e após as desilusões em relação a Nero, Sêneca acabou se afastando da casa imperial em 62 d.C. Posteriormente, em 65 d.C., o seu nome foi citado numa conspiração contra Nero e, por determinação do imperador, ele foi obrigado a suicidar-se.

A obra de Sêneca, no que diz respeito a uma representação do principado de Cláudio, pode ser separada em dois momentos - antes e depois da morte desse imperador -, expressos tanto na Consolação a Políbio quanto na sátira Apocolocintose. A Consolatio, gênero literário caracterizado por ser um texto enviado a alguém levando recomendações de caráter filosófico para enfrentar uma situação adversa, é usada para tecer elogios a Cláudio. ${ }^{8}$ Assim, Sêneca pretendia, como afirmamos, mediante a intervenção do liberto imperial, abrandar o imperador e, por conseguinte, obter o seu perdão.

$\mathrm{Na}$ Consolatio enviada por Sêneca a Políbio, o poeta representou Cláudio da seguinte forma:

Abstine ab hoc manus tuas, Fortuna, nec in isto potentiam tuam nisi ea parte qua prodes ostenderis! Patere illum generi humano iam diu aegro et adfecto mederi, patere quicquid prioris principis furor concussit in suum locum restituere ac reponere! Sidus hoc, quod praecipitato in profundum et demerso in tenebras orbi refulsit, semper luceat! Hic Germaniam pacet, Britanniam aperiat, et patrios triumphos ducat et nouos: quorum me quoque spectatorem futurum, quae ex uirtutibus eius primum optinet locum, promittit clementia. Nec enim sic me deiecit, ut nollet erigere, immo ne deiecit quidem, sed impulsum a Fortuna et cadentem sustinuit, et in praeceps euntem leniter diuinae manus usus moderatione deposuit: deprecatus est pro me senatum et uitam mihi non tantum dedit, sed etiam petit. Viderit: qualem uolet esse, existimet causam meam; uel iustitia eius bonam perspiciat, uel clementia faciat bonam: utrumque in aequo mihi eius beneficium erit, siue innocentem me scierit esse, siue uoluerit. Interim magnum miseriarum mearum solacium est uidere misericordiam eius totum orbem peruagantem: quae cum ex ipso

${ }^{7}$ Cf. Griffin, M. Seneca. A philosopher in politics. London: Oxford University Press, 2003, p. 132.

${ }^{8}$ Cf. Scourfield, J. H. D. Consolation. In: Hornblower, Simon and Spawforth, Antony (Ed.). The Oxford classical dictionary. 3. ed. Oxford: Oxford University Press, 1996, p. 378. 
angulo quo ego defixus sum complures multorum iam annorum ruina obrutos effoderit et in lucem reduxerit, non uereor ne me unum transeat. Ipse autem optime nouit tempus quo cuique debeat succurrere; ego omnem operam dabo, ne peruenire ad me erubescat. O felicem clementiam tuam, Caesar, quae efficit ut quietiorem sub te agant uitam exsules quam nuper sub Gaio egere principes! Non trepidant, nec per singulas horas gladium exspectant, nec ad omnem nauium conspectum pauent; per te habent, ut Fortunae saeuientis modum, ita spem quoque melioris eiusdem ac praesentis quietem. Scias licet ea demum fulmina esse iustissima, quae etiam percussi colunt. $^{9}$

A partir da leitura dessa passagem da Consolatio, podemos perceber que o então exilado constrói uma representação de Cláudio como um homem clemente. Nela, o autor expressou sua convicção de que o imperador, por meio de decisões acertadas, poupar-se-ia do mesmo destino que tiveram outros grandes nos tempos de Caio César Calígula.

Do exame desse excerto, surge ainda a questão: por que uma carta de consolação a um liberto conteria tantos elogios a seu senhor? Essa adulação feita a Cláudio, de modo indireto, exemplifica um comportamento

\footnotetext{
${ }^{9}$ Sêneca, Consolação a Políbio XIII: Afasta dele tuas mãos, ó sorte, nem mostres tua força nele exceto naquilo em que és favorável! Deixa que ele cure o gênero humano já há muito tempo doente e enfraquecido, deixa que ele reintegre e reponha em seu lugar o que quer que a fúria do príncipe anterior tenha abalado! Aquele astro que brilhou, precipitado o mundo nas profundezas e mergulhado nas trevas, brilhe para sempre! Que ele pacifique a Germânia, franqueie a Britânia e conduza os triunfos do pai e os novos! A clemência, que alcança o primeiro lugar entre suas qualidades, promete que eu também serei observador deles. Na verdade, não me derrubou com intentos de nunca reerguer, ou melhor, sequer me derrubou, mas segurou-me impelido pela sorte e a cair, $e$, indo abaixo, suavemente pousou-me com brandura usando as mãos divinas: implorou ao Senado por mim e não só me entregou a vida, como ainda a pediu. Estará sob seu arbítrio: pondere ele de que tipo quererá que seja minha causa; ou sua justiça note que élícita ou a clemência a faça lícita. Um e outro benefício seu será o mesmo para mim, quer entenda que sou inocente, quer o deseje. Enquanto isso, um grande consolo de minhas infelicidades é ver sua misericórdia percorrendo o mundo inteiro: ela, porque do próprio deserto onde fui encerrado desencavou a muitos oprimidos por uma desgraça já de longos anos e os reconduziu à luz, não temo que omita apenas a mim. Mas conhece bem o tempo em que deve socorrer a cada um; darei toda a atenção a que não se envergonhe de vir até mim. Ó propícia clemência tua, César, que faz com que sob ti os exilados levem uma vida mais sossegada do que há pouco sob Gaio levaram os grandes! Não tremem, nem a cada hora esperam a espada, nem se apavoram à toda visão de navios; por ti têm, assim como um termo da sorte ingrata, também a esperança de uma melhore o sossego do presente. Pode-se saber com certeza que são muito justos os raios a que mesmo os atingidos veneram! (tradução de Matheus Trevizam).
} 
comum da sociedade romana durante o principado: o servilismo. $\mathrm{Ou}$ podemos ainda pensar na hipótese de que tal atitude fosse uma ação frustrada para tentar evitar precisamente isso: nesse caso, ao endereçar a carta ao liberto e não ao imperador, Sêneca, procurando desvencilharse de um comportamento comum entre a aristocracia, acabaria realizando uma atitude considerada ainda mais baixa e subserviente: tecer louvores a um liberto.

O processo foi estudado por Sailor ${ }^{10}$ em obra sobre Tácito na qual o pesquisador comenta o servilismo instaurado no principado e reflete sobre o modo como o status do princeps passou a ser mais elevado que o dos demais membros da sociedade. As carreiras dos aristocratas mais importantes passaram, assim, a depender grandemente do imperador. As honras deixaram de ser apenas um prêmio pelas virtudes e se tornaram um estímulo à adulação sistemática ao imperador.

Uma questão chave possível para se observar essa perspectiva do autor é a análise do mártir como um modelo negativo. Ele seria, para Tácito, aquele que buscava a autonomia, ou seja, o que não se curvava à adulação. Seu comportamento não condiz com o da maioria da elite senatorial, mas tampouco constitui uma oposição efetiva ao princeps: ele prefere desfazer-se de sua vida a entrar em atrito contra a ordem vigente que só se pode contestar de forma ineficaz e perigosa.

Segundo Trevizam, ${ }^{11}$ Sêneca compartilha desse comportamento típico dos senhores do período imperial, mas fez um uso malsucedido da adulação para obter o perdão de Cláudio. Nas palavras de Paratore:

Sob o fragor do castigo sofrido, Sêneca, como Ovídio, vacilou e vergou-se a queixumes de pouca dignidade (...) As adulações soam tanto mais insinceras quanto, anos depois, Sêneca haveria de pôr a ridículo, cruelmente, o imperador no Ludus à memória do mesmo. ${ }^{12}$

Este comportamento oportunista e volúvel da aristocracia também é representado em outra obra de Sêneca, Apocolocintose, na qual o poeta cria uma representação de um Senado envolvido em corrupção e troca de favores. Não há um tratamento entre iguais, como era de se esperar.

\footnotetext{
${ }^{10}$ Cf. Sailor, D. Writing and empire in Tacitus. Cambridge: University Press, 2008.

${ }^{11}$ Sêneca. Consolação a Políbio. Trad. Matheus Trevizam. Belo Horizonte: UFMG, 2007, p. 7-8.

${ }^{12}$ Paratore, E. Historia da Literatura latina. Trad. Manuel Losa. Lisboa: Calouste Gulbenkian, 1987, p. 583.
} 
O autor usa, por exemplo, de ironia para descrever os debates no Senado celeste, construído em claro paralelo com o terrestre:

Variae erant sententiae, et uidebatur Claudius sententiam uincere. Hercules enim, qui uideret ferrum suum in igne esse, modo huc modo illuc cursabat et aiebat: "Noli mihi inuidere, mea res agitur: deinde tu si quid uolueris, in uicem faciam; manus manum lauat".

Na sátira menipeia que fora escrita após o falecimento de Cláudio, sya representação é totalmente diferente da presente em Consolação a Políbio. Em Apocolocintose, Cláudio é representado como um tirano, um déspota que teria levado muitos ao suplício pela vontade e intriga de suas mulheres e de seus libertos. Diz-nos Sêneca, pela voz de Augusto, um dos personagens da Sátira usado como modelo de bom imperador neste texto:

Hic, p.c., qui uobis non posse uidetur muscam excitare, tam facile homines occidebat, quam canis excidit. Sed quid ego de tot ac talibus uiris dicam? Non uacat deflere publicas clades intuenti domestica mala. $^{14}$

Nesta passagem, fica claro que Sêneca desfaz toda a ideia expressa na Consolação a Políbio sobre a clemência de Cláudio. Para ele, o falecido imperador fora cruel e se afastara dos senadores, que parecem tão pouco dignos no geral quanto o próprio Cláudio. A exceção aqui será Augusto. Deste modo, Sêneca não elogia o Senado para criticar Cláudio. A proposição senequiana, assim, não se dirige ao chamado "ideal senatorial". Para Faversani:

A imagem que Sêneca impõe ao Senado não foi criada ex nihilo. Como havia quem falasse dos "maus imperadores", por certo existia quem amaldiçoasse os "maus senadores". E Sêneca afirma em Apocolocyntosis que, à época de Cláudio, e, antes dele, nos tempos de Calígula,

\footnotetext{
${ }^{13}$ Sêneca, Apocolocintose IX, 6: As opiniões estavam divididas; e Cláudio parecia sair vencedor: de fato, Hércules, batendo oferro enquanto estava quente, corria continuamente, sussurrando a cada um: "Não me negues este favor, é para mim uma questão pessoal. Amanhã, se precisares, retribuirte-ei: uma mão lava a outra" (tradução de Frederico Sousa Silva).

${ }^{14}$ Sêneca, Apocolocintose X, 3: Este sujeito, ó senadores, que vos parece incapaz de maltratar um mosquito, matara os homens com a mesma facilidade com a qual um cão levanta a pata. Mas para que lembrarei eu tantas e tão ilustres vítimas? Não tem tempo para chorar as desventuras da pátria quem olha para os lutos domésticos (tradução de Frederico Sousa Silva).
} 
imperadores e Senado estavam totalmente alheios ao papel que deveriam desempenhar. ${ }^{15}$

Atentando para o contexto de produção da obra, não podemos esquecer que a classe senatorial criticada pelo filósofo é a mesma da qual ele faz parte. Ainda mais, devemos ter em mente que a composição do Senado não mudou muito entre o tempo de escrita da Consolatio e da sátira. Conclui-se que Sêneca, na Consolatio ad Polybium, não agiu de modo diferente daquele que criticou em Apocolocintose.

$\mathrm{Na}$ sátira, Sêneca apresenta os acusadores entristecidos com a morte de Cláudio, pois estes eram os maiores favorecidos com a política de perseguições promovida pelo imperador. De acordo com a composição senequiana, os advogados também se lamentavam, já que Cláudio os prestigiava em detrimento dos iurisconsulti. A regularidade jurídica voltaria das trevas à luz com a morte de Cláudio. ${ }^{16}$ A clemência tão louvada em Consolação a Políbio cede espaço para um Cláudio que executava indiscriminadamente os cidadãos romanos, estabelecendo uma espécie de reino do terror. É isso que se reafirma na passagem em que Sêneca reforça a noção de obediência aos marcos legais para destacar um elevado número de vítimas (trinta e cinco senadores, duzentos e vinte e um cavaleiros e tantos outros). ${ }^{17}$

\footnotetext{
${ }^{15}$ Faversani, F. A sociedade em Sêneca. Tese inédita de doutorado. São Paulo: Universidade de São Paulo, 2001, p. 138.

${ }^{16}$ Sêneca, Apocolocintose XII, 2: Populus Romanus ambulabat tanquam liber, Agatho et pauci causidici plorabant, sed plane ex animo. Iurisconsulti e tenebris procedebant, pallidi, graciles, uix animam habentes, tanquam qui tum maxime reuiuiscerent. Ex his unus cum uidisset capita conferentes et fortunas suas deplorantes causidicos, accedit et ait: "Dicebam uobis: non semper Saturnalia erunt". - "O povo romano andava como um povo livre. Ágato e uns poucos advogados choravam, mas inteiramente de coração. Os juriconsultos saíam das sombras, pálidos, franzinos, como exatamente quem então tornassem à vida. Um desses juízes, quando teria visto os que se reuniam e os advogados que choravam suas sortes, aproximou-se lhes e disse: "Eu vos falava: não haverá sempre as Saturnais" (tradução de Frederico Sousa Silva).

${ }^{17}$ Sêneca, Apocolocintose XIV, 1: Ducit illum ad tribunal Aeaci: is lege Cornelia quae de sicariis lata est, quaerebat. Postulat, nomen eius recipiat; edit subscriptionem: occisos senatores XXXV, equites R. CCXXI, ceteros "hósa psámathos te kónis te" - "Conduzia-o ao tribunal de Éaco, que buscava na lei Cornélia os dizeres a respeito dos assassinos. [Pedo] solicita que acolha o nome de Cláudio. Entrega a acusação: 35 senadores assassinados, 221 cavaleiros Romanos e outros tantos como a arena ou o polvo" (tradução de Frederico Sousa Silva).
} 
Diante desse cenário, são os aduladores que têm maiores chances de sobreviver em um mau principado. Por consequência, o principado de Cláudio acaba sendo marcado por um servilismo dessa aristocracia para com o imperador e seus próximos. Quando Cláudio morre, o que é mais exaltado por Sêneca é que agora o povo romano andava como um povo livre (XII, 2: Populus Romanus ambulabat tanquam líber importante destacar o uso de tanquam). Ou seja, pode-se dizer que Sêneca muda radicalmente seu juízo sobre Cláudio. Contudo, mantém o princípio de que, sob um mau governante, só resta à aristocracia adular (mesmo que a adulação mereça ser criticada, sobretudo quando desmedida).

A outra concepção presente de forma direta na sua bajulação a Cláudio é a de governante ideal. Sêneca se concentra, sobretudo, no tema da clemência. Para ele, essa seria a virtude mais importante para o governante e o exercício desta distinguiria as pessoas normais dos sábios, aqueles que mais se aproximariam dos deuses. Por isso, na Consolatio, o poeta fala repetidamente sobre a clemência.

Mas foi em De clementia que nosso escritor realmente desenvolveu a ideia de governante ideal, ligando-a àquela de clemência. Essa obra, que teria sido uma espécie de manual para o governo de Nero, de quem Sêneca foi preceptor, sugere empregar-se a clemência tanto para o governante quanto para a população, e apresenta uma série de exemplos de como essa virtude poderia ser confundida com os vícios que lhe eram correlatos ou, ainda, como, praticada indiscriminadamente, a mesma qualidade poderia conduzir ao erro. Uma das passagens em que afirma a importância da clemência mostra que

Clementia, in quamcumque domum peruenerit, eam felicem tranquillamque praestabit, sed in regia, quo rarior, eo mirabilior. Quid enim est memorabilius quam eum, cuius irae nihil obstat. ${ }^{18}$

Faversani analisa, em sua tese citada anteriormente, que Sêneca via o imperador e o povo fundidos em um só corpo. E como cabeça deste, o governante deveria ponderar sobre seus atos, não apenas agindo sobre seus impulsos, mas também se abstendo de colocar suas vontades à frente do bem comum:

\footnotetext{
${ }^{18}$ Sêneca, Tratado sobre a Clêmencia I, V: A clemência, em qualquer casa que entre, the será pacífica e feliz, mas no palácio é mais rara e muito mais admirável. Porque o que mais vale lembrar que aquele, cuja raiva não tem obstáculos (tradução de Ingeborg Braren).
} 
Assim, o que se vê é que o Imperador ideal de Sêneca é aquele que se funde com o povo, incorpora a Res Publica em si e, mostrando-se à altura dos deuses, deles recebe seu favor. Um Imperador povo-Estadodeus. Algo muito distante do "ideal senatorial". O Imperador de Sêneca é "o homem cuja cólera não encontra nenhuma oposição" (III, III, 4) já "que tem poder sobre todas as coisas" (III, III, 6). O que deveria conter o Imperador seria sua própria "clemência", como indica o título do tratado senequiano. ${ }^{19}$

Com base no contexto histórico do principado, no qual o acesso ao imperador era muito restrito e a disputa política na época, justamente demarcada pela busca de uma proximidade maior com o princeps, podemos entender o porquê de os elogios a Cláudio terem seguido em uma carta de consolação a um liberto. Quanto mais próximo do imperador, mais poder e capacidade de influenciar na política romana possuía o indivíduo. Ao mesmo tempo, a carta consolatória indica que o imperador não tomava decisões sozinho, mas era influenciado por conselheiros.

O imperador-sábio do De clementia parece sempre decidir só, estando acima e a favor de todos os demais. No caso do principado de Cláudio, percebemos que a carta se dirigia a uma das pessoas que ele costumava ouvir para tomar decisões. E aqui reside justamente uma das críticas que comumente é feita a Cláudio: especialmente após sua morte, foi contestado o considerável poder dado por ele aos libertos e às mulheres, o qual causou grande descontentamento na aristocracia romana.

Pela necessidade de adular para conquistar algo, Sêneca recorre a elogios ao imperador por meio de uma carta ao liberto Políbio, responsável pela correspondência imperial, e que, na visão de Sêneca, poderia interceder junto a Cláudio para alcançar-lhe um indulto. Tal era o servilismo que passou a caracterizar as relações entre os súditos e o imperador, atitude ainda mais destacada quando coloca um homem de origem elevada solicitando e dependendo do julgamento de uma pessoa de origem escrava. Os aristocratas se portariam, assim, de forma servil, uma vez que teriam em vista seu interesse pessoal mais do que o interesse público e não reconheceriam as hierarquias. ${ }^{20}$ Sêneca também o fez, como mostra a Consolatio. Para que o valor dos aristocratas pudesse

\footnotetext{
${ }^{19}$ Cf. Faversani, op. cit., p. 140.

${ }^{20}$ Esta percepção da escravidão como uma metáfora de difundido uso político na literatura do principado é estudada por Fábio Duarte Joly em sua tese de doutorado [Joly, F. D. Libertate opus est. Escravidão, manumissão e cidadania à época de Nero (54-68 d.C.). Tese de doutorado inédita. São Paulo: Universidade de São Paulo, 2006].
} 
voltar a se afirmar, caberia inverter o impulso negativo que vinha do imperador.

Nas mesmas obras é possível perceber outra concepção de Sêneca: o governante ideal seria aquele que estivesse acima dos demais não só pelo poder que detinha, mas pela sabedoria e pelas virtudes. Ele regularia todas as disputas na sociedade romana porque detinha mais poder do que qualquer um dos demais. Mas esse poder supremo apenas estimularia a existência de uma sociedade virtuosa se ele mesmo fosse modelo máximo de virtude. Para tal soberano, a virtude mais importante seria a clemência. Seria essa a qualidade que separava os interesses pessoais das tarefas de Estado, e o imperador, sendo o mais sábio entre todos, seria o único que poderia se livrar de emoções, como a raiva, e exercer a justa clemência. Podemos interpretar que, ao elogiar a suposta clemência de Cláudio, Sêneca estaria lançando bases para sua imagem de governante ideal, a ser desenvolvida no De clementia.

Em conclusão, podemos perceber que Sêneca oferece importantes elementos para problematizarmos os dilemas com os quais se defrontavam os aristocratas sob o principado. O que destacamos neste artigo foi apenas um entre diversos destes elementos presentes ao longo da obra desse pensador. Para viver virtuosamente, os aristocratas dependiam em larga medida da existência de um imperador virtuoso. Sob um imperador sem virtudes, sobretudo um que não fosse clemente, os aristocratas ficavam entre dois extremos. O primeiro deles seria adular, agindo servilmente frente ao imperador, mas aumentando suas possibilidades de preservar a vida e ainda assegurar vantagens imediatas. O outro extremo era contrapor-se ao imperador, o que significaria perder a vida ou, ao menos, as vantagens que o imperador podia oferecer. O que Sêneca deixa claro é que encontrar um ponto intermediário positivo entre estes dois extremos, ambos negativos, não era fácil. Ou seja, o surgimento de uma aristocracia virtuosa se colocaria em direta dependência do surgimento de um imperador virtuoso. Se seguir o imperador e elogiá-lo parece ser inescapável, então a melhor forma para não ser bajulador é elogiar e seguir a um homem sábio e virtuoso. Cabe à aristocracia submeter-se ao imperador. E espera-se que o imperador preserve a aristocracia do desastre de transformar essa submissão um ato de servilismo. Como se vê, era um cenário quase impossível: de fato, não existiu. 


\section{Referências}

FAVERSANI, F. A sociedade em Sêneca. Tese de doutorado inédita. São Paulo: FFLCHUSP, 2001.

GRIFFIN, M. Seneca. A philosopher in politics. London: Oxford University Press, 2003. GRIMAL, P. Sénèque. Paris: Fayard, 1978.

JOLY, F. D. Libertate opus est. Escravidão, manumissão e cidadania à época de Nero (54-68 d.C.). Tese de doutorado inédita. São Paulo: FFLCH-USP, 2006.

JOLY, F. D. Tácito e a metáfora da escravidão. Um estudo de cultura política romana. São Paulo: Edusp, 2004.

PARATORE, E. Historia da Literatura latina. Trad. Manuel Losa. Lisboa: Calouste Gulbenkian, 1987.

PETRONIUS; SENECA. Satyricon; Apocolocyntosis. With an English translation by W. H. D. House. London: Harvard University Press, 1927.

SAILOR, D. Writing and empire in Tacitus. Cambridge: University Press, 2008.

SCOURFIELD, J. H. D. Consolation. In: HORNBLOWER, Simon; SPAWFORTH, Antony (Ed.). The Oxford classical dictionary. 3. ed. Oxford: University Press, 1996. p.378. SÊNECA. Consolação a Políbio. Trad. Matheus Trevizam. Belo Horizonte: UFMG, 2007. . Tratado sobre a Clemência. Tradução e notas de Ingeborg Braren. Petrópolis: Vozes, 1990.

. De la clémence. Texte établi et traduit par François-Régis Chaumartin. Paris: Les Belles Letres, 2005.

Dialogues. Tome troisième: Consolations. Texto établi et traduit par René Waltz. Paris: Les Belles Lettres, 1942.

SILVA, F. S. Apocolocintose do Divino Cláudio. Tradução, notas e comentários. Dissertação de mestrado inédita. São Paulo: FFLCH-USP, 2008.

SUÉTONE. Vies des douze Césars. Tome II: Tibère-Caligula-Claude - Néron. Texte établi et traduit par Henri Ailloud. Paris: Les Belles Lettres, 2002.

TACITUS. Annals. With an English translation by John Jackson. London: Harvard University Press, 1926.

TACITUS. Annales. With an English translation by A. J. Woodman. Indianápolis: Hackett Publishing Company, 2004.

WALTZ, R. Vie de Sénèque. Paris: Perrin, 1909.

WIEDEMAN, T. E. J. Tiberius to Nero. In: BOWMAN, A. K.; CHAMPLIN, E.; LINTOTT, A. (Org.). Cambridge Ancient History. Vol. X. The Augustan empire, 43 B.C. -A.D. 69. Cambridge: University Press, 2008, p. 198-255. 